\title{
Relation of carbohydrate exchange markers with vitamin D status in adolescents with overweight and obesity
}

Korelacja markerów przemiany węglowodanów ze stężeniem witaminy D u nastolatków z nadwagą i otyłością

\author{
Anna-Mariia Shulhai ${ }^{1}$, Halyna Pavlyshyn ${ }^{1}$, Oleksandra Shulhai ${ }^{2}$
}

${ }^{1}$ Department of Pediatrics №2, I. Horbachevsky Ternopil National Medical University, Ukraine

${ }^{2}$ Department of Children's Diseases with Pediatric Surgery, I. Horbachevsky Ternopil National Medical University, Ukraine

\begin{abstract}
Introduction: In the case of obesity and excessive body weight, the deficiency of vitamin D increases, which significantly impairs metabolic processes in the body, especially fatty and carbohydrate metabolism. Vitamin D metabolites affect insulin sensitivity of cells. The aim of the study was to determine the relationship between vitamin D and carbohydrate metabolism in adolescents with excessive body weight and obesity.

Material and methods: 139 adolescents were examined. The mean age of children was $15.5 \pm 2.3$ years. 65 adolescents with excessive weight and 74 obesity teenagers were examined. Parameters that were determined in all children included: undertaking anthropometric measurements, general examinations, biochemical parameters, including carbohydrate metabolism: fasting glucose, insulin, oral glucose tolerant test, measuring the homeostasis model assessment for insulin resistance, blood pressure measurement and determination of vitamin D status.

Results: The features of changes carbohydrate metabolism markers in adolescents with overweight and obesity, depending on the level of serum 25(OH)D, have been established. Correlations between vitamin D status and markers of carbohydrate metabolism such as basal insulin level $(p=0.000)$ and HOMA-IR index $(p=0.000)$ and anthropometric indices: body mass index $(p=0.000)$, waist circumference $(p=0.000)$ and hip circumference $(p=0.001)$, waist-hip ratio $(p=0.000)$, waist-to-height ratio $(p=0.000)$ have been determined.

Conclusions: The study has established prognostically significant biochemical (basal insulin), and anthropometric (body mass index, waist circumference, waist-hip ratio, and waist-to-height ratio) markers resulting in vitamin D deficiency development in children with excessive body weight and obesity.
\end{abstract}

Key words:

obesity, adolescent, vitamin D, carbohydrate metabolism. 


\section{Introduction}

Childhood obesity is an important public health problem. Obesity reaches $17.2 \%$ among endocrine diseases in Ukraine [1]. Out of all children with overweight and obesity, about $51 \%$ are between the ages of 14 and 17 years [2]. Due to overweight and obesity, metabolic disturbances, including carbohydrate and lipid metabolism disorders, develop and present cardiometabolic risk factors [3, 4], which further increase the risk of disability and premature death. The basis of the pathogenesis of metabolic disorders in obesity is insulin resistance syndrome, which is one of the leading factors in the development of cardiovascular diseases. With insulin resistance, fat, muscle, endothelial, and hepatic tissues are affected most of all [4, 5].

Prolonged increase of glucose and fatty acids in the blood affects the function of $\beta$-cells of the pancreas, and ultimately leads to a decrease in insulin secretion.

In the case of obesity as well as overweight, the deficiency of vitamin $D$ increases, which greatly aggravates metabolic processes in the body. Vitamin D metabolites increase insulin sensitivity to insulin due to increased insulin receptor gene expression and decreased inflammatory cytokines [6, 7].

In peripheral target cells, active metabolites of vitamin D increase insulin sensitivity, including increased expression of receptors, activating transcription factors that are important for glucose homeostasis [8, 9], or acting indirectly through the regulation of calcium, which is required for insulin-associated intracellular processes.

\section{Aim of the study}

The aim of the given research was to determine the relationship between vitamin D and carbohydrate metabolism in adolescents with overweight and obesity.

\section{Material and methods}

The research was conducted on the basis of the communal institution of the Ternopil Regional Council: Ternopil Regional Children's Clinical Hospital. In carrying out the research, the rules of patient safety and ethical principles of conducting scientific medical research with the participation of human subjects (2013) were observed. The Commission on Bioethics of the I. Horbachevsky Ternopil State Medical University granted permission to carry out this study.

A total of 139 adolescents were examined, among whom, depending on the body mass index (BMI), 65 had overweight and 74 had obesity. Out of all participants, there were $63(45.4 \%)$ girls and 76 (54.7\%) boys. The mean age of children was $15.4 \pm 2.3$ years.

Evaluation of pubertal development was carried out according to Tanner criteria (stages 2-5). In order to compare serum calcidiol levels in adolescents with overweight and obesity, and calcidiol levels in adolescents with normal body weight
(BMI less than $85^{\text {th }}$ percentile for the given age and gender), a control group of 63 healthy children who were of comparable gender and age to comparison groups was presented.

The inclusion criteria for the study were the following: body mass index of more than $85^{\text {th }}$ percentile for overweight children and over $97^{\text {th }}$ percentile for obesity, according to age-sex nomograms, written informed consent of parents and patients for the examination, autumn-winter period.

To determine vitamin $D$ status using the immune-enzyme method, blood serum levels of $25(\mathrm{OH}) \mathrm{D}$ were determined. Thus, 25-OH Vitamin D ELISA kit (EUROIMMUN, Germany) was used, with an intra-assay CV of 3.2-4.9\% and an inter-assay CV of $4.0-7.8 \%$. The assessment of the results of the $25(\mathrm{OH}) \mathrm{D}$ level was conducted according to the recommendations of the International Society of Endocrinologists [10]. In order to differentiate the relationship between vitamin $D$ level and parameters of carbohydrate metabolism and anthropometric measurements, adolescents with overweight and obesity were divided into four subgroups, according to the level of calcidiol in blood serum. Subgroup 1 included 37 adolescents with 25(OH)D level less than $10 \mathrm{ng} / \mathrm{ml}$, subgroup 2 included 71 adolescents with 25(OH)D level from $10 \mathrm{ng} / \mathrm{ml}$ to $20 \mathrm{ng} / \mathrm{ml}$, subgroup 3 included 22 adolescents with 25(OH)D level from $20 \mathrm{ng} / \mathrm{ml}$ to $30 \mathrm{ng} / \mathrm{ml}$, and subgroup 4 included 9 adolescents with 25(OH)D level more than $30 \mathrm{ng} / \mathrm{ml}$.

Anthropometric examinations: body weight was measured using electronic scales (within accuracy $0.1 \mathrm{~kg}$ ), height by means of a stadiometer (accuracy $0.1 \mathrm{~cm}$ ), and waist circumference and hip circumference using a flexible measuring tape (within accuracy of $0.1 \mathrm{~cm}$ ). Then the waist-hip ratio $(\mathrm{WHR})$ was calculated as WC divided by HC. BMI was calculated according to the formula (mass $[\mathrm{kg}] /$ height $^{2}\left[\mathrm{~m}^{2}\right]$ ). The waist-to-height ratio (WHtR) was defined as WC divided by height. BMI Z-score (BMIz) was calculated according to the formula (observed value - median value of the reference population)/standard deviation value of reference population, for world health organisation (WHO) recommendation [11].

BMI was assessed by percentile curves for girls and boys separately according to WHO charts and tables. Overweight was diagnosed in cases where BMI was higher than $85^{\text {th }}$ to $97^{\text {th }}$ percentile, and obesity when BMl exceeded $97^{\text {th }}$ percentile according to gender and age. The adjusted measures of relative weight adjusted for age and sex were evaluated by the BMIz.

Measurement of blood pressure (BP) was performed on both upper limbs three times in a sitting position using a mechanical sphygmomanometer with a cuff.

To evaluate the carbohydrate metabolism, an oral glucose tolerance test was performed to determine the level of fasting glucose and insulin in blood and at 30, 60, 120, and 180 minutes after glucose loading. Blood glucose levels were determined by the glucose oxidase method, and blood insulin levels were measured by ELICA (immunochemical with electrochemiluminescent detection) using a Cobas 6000 analyser and Roche Diagnostics test systems (Switzerland). The HOMA-IR (Homeostasis Model Assessment for Insulin Resistance) index was calculated by the formula: HOMA IR $=$ (fasting glucose $\times$ 
fasting insulin)/22.5. Insulin resistance was detected at values of HOMA-IR 3.19 and higher [9].

\section{Statistical analysis}

The statistical processing of the results of the conducted studies was carried out using statistical package "STATISTICA 10.0" and table editor "Microsoft Excel 2003". The assessment of the normality of the distribution of features in the variation series was carried out according to the Kolmogorov-Smirnov criterion. Given the correct distribution, the quantitative data was presented as mean values (M) and their standard errors (SD). In the presence of an incorrect distribution of quantities, the quantitative data was presented as median (Me) and interquartile range, or mean values $(\mathrm{M})$, and $95 \%$ confidence interval $(95 \% \mathrm{Cl})$. A comparison of two independent samples with the correct distribution was performed using the Student's t-criterion, and in the case of an incorrect distribution of values - using the nonparametric U-Mann-Whitney U-criterion. The comparison of frequency indices in the observation groups was performed using criterion $\chi^{2}$. Correlation analysis was performed to estimate the relation between the Spearmen correlation coefficient and multiple regression analysis.

Significance of the differences between the values was considered significant at $p<0.05$.

\section{Results}

In adolescents, a low level of calcidiol in blood plasma is determined. The results of the examination of $25(\mathrm{OH}) \mathrm{D}$ in blood serum of adolescents with normal body weight, overweight, and obesity are presented in Figure 1.

Average values of $25(\mathrm{OH}) \mathrm{D}$ in the serum of children with normal body weight were $19.76 \pm 4.28 \mathrm{ng} / \mathrm{ml}$, in overweight adolescents - $15.24 \pm 3.47 \mathrm{ng} / \mathrm{ml}$, and in obese children - 13.87 $\pm 2.71 \mathrm{ng} / \mathrm{ml}$. These data showed that the average values of serum calcidiol levels were 1.23 times higher than those in the overweight group $(p=0.012)$ and 1.43 times higher than in obese children $(p=0.000)$ [2].

The comparative analysis of anthropometric indices, BP, and carbohydrate metabolism parameters was performed depending on the 25(OH)D level (Tables I, II). It was established that as the serum calcidiol level decreases, there was a significant increase in body weight, an increase in the body mass index, an increase of BMlz, an increase in the circumference of the waist and hip, and an increase in the waist-hip ratio, and waist-height ratio increased. There was no established difference in the growth of adolescents when comparing subgroups with different levels of vitamin D blood saturation.

The level of systolic and diastolic blood pressure in overweight and obese adolescents did not present a significant difference between the subgroup distribution of $25(\mathrm{OH}) \mathrm{D}$ concentration. The lowest BP values were seen in the subgroup of children with sufficient levels of vitamin D in blood serum.

Among the indicators that characterise the carbohydrate metabolism, the dependence on vitamin D level was deter- mined. The level of basal insulin in the blood of children in subgroup 1, with the pronounced deficiency of vitamin $D$, was $27.8 \mu \mathrm{O} / \mathrm{ml}$, and it was 1.32 times $(p=0.000)$ higher than in children with vitamin $\mathrm{D}$ deficiency, who were assigned to the second subgroup, and their basal insulin level was $21.1 \mu \mathrm{O} / \mathrm{m}$, 1.85 times $(p=0.000)$ higher than in the third subgroup of adolescents with vitamin $D$ insufficiency with basal insulin level $15.1 \mu \mathrm{O} / \mathrm{ml}$, and 1.81 times $(p=0.000)$ higher than the fourth subgroup with sufficient vitamin $D$ level with basal insulin level $15.4 \mu \mathrm{O} / \mathrm{ml}$ (Table II).

The average blood glucose level in children with overweight and obesity in all four subgroups of the study was within the range $5.0 \mathrm{mmol} / \mathrm{l}-5.4 \mathrm{mmol} / \mathrm{l}$ and showed no significant difference $(\rho>0.05)$. The index of insulin resistance HOMA-IR depended largely on the level of basal insulin in the blood and was associated with vitamin D. The tendency of HOMA-IR to increase grows rapidly with a decrease in $25(\mathrm{OH}) \mathrm{D}$ concentration

In $7.2 \%$ of adolescents with overweight and obesity, glucose intolerance was detected, which was not relevant concerning the calcidiol level in plasma.

The impaired fasting glycaemia in the general group of adolescents with overweight and obesity was $27.4 \%$ and was characterised by higher values in children with severe deficiency and vitamin D deficiency. In the comparative assessment of glycaemic disturbances in the subgroup distribution of $25(\mathrm{OH}) \mathrm{D}$, the frequency in subgroup 1 was 1.49 times higher, and in subgroup 4 it was 2.42 times higher.

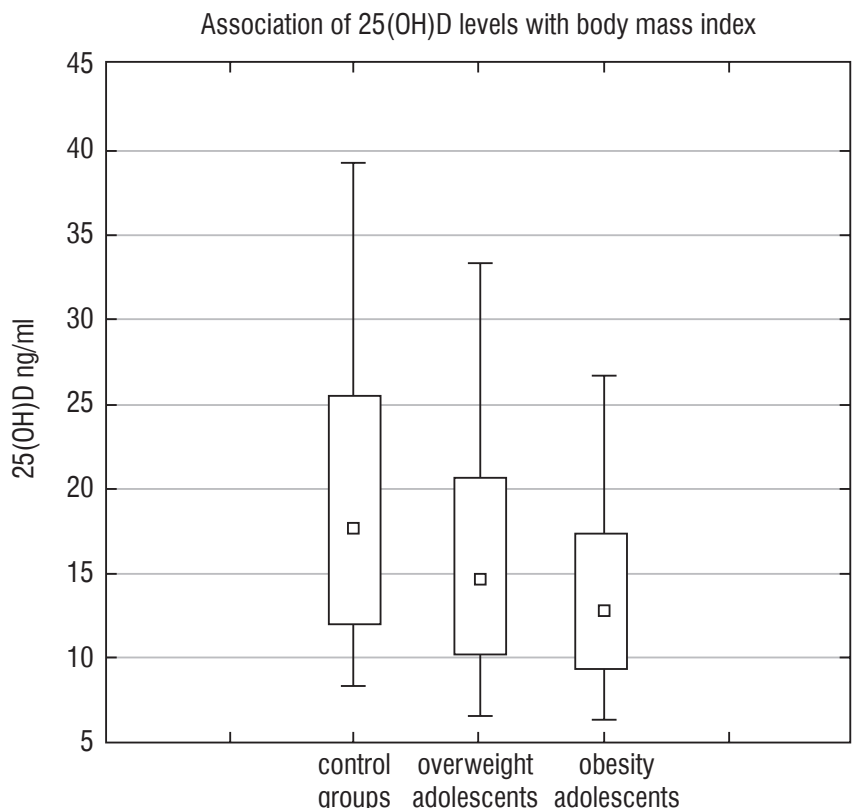

groups adolescents adolescents

$$
\text { a median } \square 25-75 \% \text { 工 non-outlier range }
$$

Figure 1. 25(OH)D content in blood serum of adolescents with normal weight, excessive body weight and obesity 
Table I. Characteristics of anthropometric indices and blood pressure in overweight and obese adolescents, depending on the 25(OH)D levels, Me $(95 \% \mathrm{Cl})$

\begin{tabular}{|c|c|c|c|c|c|}
\hline Parameters & $\begin{array}{l}\text { Subgroup } 1 \\
n=37\end{array}$ & $\begin{array}{l}\text { Subgroup } 2 \\
n=71\end{array}$ & $\begin{array}{l}\text { Subgroup } 3 \\
n=22\end{array}$ & $\begin{array}{l}\text { Subgroup } 4 \\
n=9\end{array}$ & $\begin{array}{l}\text { Certainty } \\
\text { coefficient, } p\end{array}$ \\
\hline Body weight, kg & $\begin{array}{l}98.1 \\
(91.7-104.4)\end{array}$ & $\begin{array}{l}91.1 \\
(87.4-94.6)\end{array}$ & $\begin{array}{l}87.9 \\
(82.9-92.9)\end{array}$ & $\begin{array}{l}79.2 \\
(72.8-85.2)\end{array}$ & $\begin{array}{l}p_{1,2}=0.039 \\
p_{1,3}=0.028 \\
p_{1,4}=0.004\end{array}$ \\
\hline Height, cm & $\begin{array}{l}175.3 \\
(172.5-178.1)\end{array}$ & $\begin{array}{l}175.5 \\
(173.2-177.8)\end{array}$ & $\begin{array}{l}179.6 \\
(175.2-183.9)\end{array}$ & $\begin{array}{l}173.1 \\
(165.9-180.3)\end{array}$ & $\begin{array}{l}p_{1,2}=0.959 \\
p_{1,3}=0.076 \\
p_{1,4}=0.496\end{array}$ \\
\hline $\mathrm{BMI}, \mathrm{kg} / \mathrm{m}^{2}$ & $\begin{array}{l}31.9 \\
(30.1-33.8)\end{array}$ & $\begin{array}{l}29.5 \\
(28.6-30.3)\end{array}$ & $\begin{array}{l}27.2 \\
(26.3-28.1)\end{array}$ & $\begin{array}{l}26.3 \\
(24.7-28.1)\end{array}$ & $\begin{array}{l}p_{1,2}=0.007 \\
p_{1,3}=0.000 \\
p_{1,4}=0.005\end{array}$ \\
\hline BMlz & $\begin{array}{l}1.86 \\
(1.59-2.13)\end{array}$ & $\begin{array}{l}1.63 \\
(1.49-1.77)\end{array}$ & $\begin{array}{l}1.54 \\
(1.43-1.65)\end{array}$ & $\begin{array}{l}1.37 \\
(1.12-1.62)\end{array}$ & $\begin{array}{l}p_{1,2}=0.092 \\
p_{1,3}=0.175 \\
p_{1,4}=0.121\end{array}$ \\
\hline WC, $\mathrm{cm}$ & $\begin{array}{l}108.6 \\
(101.9-115.2)\end{array}$ & $\begin{array}{l}99.5 \\
(96.4-102.7)\end{array}$ & $\begin{array}{l}93.8 \\
(90.2-97.4)\end{array}$ & $\begin{array}{l}90.1 \\
(81.3-98.9)\end{array}$ & $\begin{array}{l}p_{1,2}=0.005 \\
p_{1,3}=0.001 \\
p_{1,4}=0.009\end{array}$ \\
\hline $\mathrm{HC}, \mathrm{cm}$ & $\begin{array}{l}115.6 \\
(110.8-120.4)\end{array}$ & $\begin{array}{l}108.2 \\
(105.9-110.5)\end{array}$ & $\begin{array}{l}105.6 \\
(102.3-108.9)\end{array}$ & $\begin{array}{l}101.2 \\
(93.3-109.1)\end{array}$ & $\begin{array}{l}p_{1,2}=0.002 \\
p_{1,3}=0.004 \\
p_{1,4}=0.047\end{array}$ \\
\hline WHR & $\begin{array}{l}0.94 \\
(0.91-0.96)\end{array}$ & $\begin{array}{l}0.92 \\
(0.90-0.94)\end{array}$ & $\begin{array}{l}0.89 \\
(0.86-0.92)\end{array}$ & $\begin{array}{l}0.88 \\
(0.84-0.93)\end{array}$ & $\begin{array}{l}p_{1,2}=0.233 \\
p_{1,3}=0.011 \\
p_{1,4}=0.072\end{array}$ \\
\hline WHtR & $\begin{array}{l}0.62 \\
(0.58-0.66)\end{array}$ & $\begin{array}{l}0.57 \\
(0.55-0.59)\end{array}$ & $\begin{array}{l}0.52 \\
(0.49-0.55)\end{array}$ & $\begin{array}{l}0.53 \\
(0.47-0.59)\end{array}$ & $\begin{array}{l}p_{1,2}=0.002 \\
p_{1,3}=0.001 \\
p_{1,4}=0.037\end{array}$ \\
\hline SBP, mm Hg & $\begin{array}{l}131.5 \\
(126.1-140.2)\end{array}$ & $\begin{array}{l}132.6 \\
(129.8-135.6)\end{array}$ & $\begin{array}{l}131.7 \\
(125.6-137.7)\end{array}$ & $\begin{array}{l}123.2 \\
(114.1-132.3)\end{array}$ & $\begin{array}{l}p_{1,2}=0.682 \\
p_{1,3}=0.968 \\
p_{1,4}=0.157\end{array}$ \\
\hline $\mathrm{DBP}, \mathrm{mm} \mathrm{Hg}$ & $\begin{array}{l}84.6 \\
(81.4-88.2)\end{array}$ & $\begin{array}{l}83.4 \\
(81.1-85.5)\end{array}$ & $\begin{array}{l}83.3 \\
(79.7-86.9)\end{array}$ & $\begin{array}{l}77.1 \\
(69.7-84.4)\end{array}$ & $\begin{array}{l}p_{1,2}=0.510 \\
p_{1,3}=0.622 \\
p_{1,4}=0.042\end{array}$ \\
\hline
\end{tabular}

BMI - body mass index; BMlz - index of relative weight; SBP - systolic blood pressure; DBP - diastolic arterial pressure; WC - waist circumference, $\mathrm{HC}$ - hip circumference; WHR - ratio of waist circumference to hip circumference, WHtR - ratio of waist circumference to height; $p_{1,2}-$ the certainty of the difference between the indices of subgroup 1 and $2 ; p_{1,3}$ - the certainty of the difference between the indices of subgroup 1 and 3 ; $p_{1,4}$ - the certainty of the difference between the indices of subgroup 1 and 4 
Table II. Characteristics of carbohydrate metabolism in adolescents with excessive body weight and obesity, depending on the subgroup distribution of $25(\mathrm{OH}) \mathrm{D}$, Me $(95 \% \mathrm{Cl})$

\begin{tabular}{|c|c|c|c|c|c|}
\hline Parameters & $\begin{array}{l}\text { Subgroup } 1 \\
n=37\end{array}$ & $\begin{array}{l}\text { Subgroup } 2 \\
n=71\end{array}$ & $\begin{array}{l}\text { Subgroup } 3 \\
n=22\end{array}$ & $\begin{array}{l}\text { Subgroup } 4 \\
n=9\end{array}$ & $\begin{array}{l}\text { Certainty } \\
\text { coefficient, } p\end{array}$ \\
\hline $\begin{array}{l}\text { Blood glucose, } \\
\mathrm{mmol} / \mathrm{l}\end{array}$ & $\begin{array}{l}5.2 \\
(5.0-5.4)\end{array}$ & $\begin{array}{l}5.3 \\
(5.1-5.5)\end{array}$ & $\begin{array}{l}5.4 \\
(5.1-5.7)\end{array}$ & $\begin{array}{l}5.0 \\
(4.5-5.4)\end{array}$ & $\begin{array}{l}p_{1,2}=0.708 \\
p_{1,3}=0.361 \\
p_{1,4}=0.365\end{array}$ \\
\hline $\begin{array}{l}\text { Basal insulin, } \\
\mu \mathrm{O} / \mathrm{ml}\end{array}$ & $\begin{array}{l}27.8 \\
(25.1-30.7)\end{array}$ & $\begin{array}{l}21.1 \\
(19.2-23.0)\end{array}$ & $\begin{array}{l}15.1 \\
(12.7-17.5)\end{array}$ & $\begin{array}{l}15.4 \\
(12.6-18.2)\end{array}$ & $\begin{array}{l}p_{1,2}=0.000 \\
p_{1,3}=0.000 \\
p_{1,4}=0.000\end{array}$ \\
\hline HOMA-IR & $\begin{array}{l}6.4 \\
(5.7-7.1)\end{array}$ & $\begin{array}{l}4.9 \\
(4.5-5.3)\end{array}$ & $\begin{array}{l}3.7 \\
(3.1-4.3)\end{array}$ & $\begin{array}{l}3.5 \\
(2.6-4.3)\end{array}$ & $\begin{array}{l}p_{1,2}=0.000 \\
p_{1,3}=0.000 \\
p_{1,4}=0.000\end{array}$ \\
\hline IGT, $n$ (\%) & $2(5.4)$ & $6(8.5)$ & $2(9.1)$ & - & $\begin{array}{l}p_{1,2}=0.567 \\
p_{1,3}=0.587\end{array}$ \\
\hline $\mathrm{IFG}, n(\%)$ & $10(27.1)$ & $23(32.4)$ & $4(18.2)$ & $1(11.2)$ & $\begin{array}{l}p_{1,2}=0.566 \\
p_{1,3}=0.440 \\
p_{1,4}=0.316\end{array}$ \\
\hline
\end{tabular}

HOMA-IR - index of insulin resistance; IGT - impaired glucose tolerance; IFG - impaired fasting glycaemia; $p_{1,2}$ - the certainty of the difference between the indicators of subgroup 1 and $2 ; p_{13}$ - the certainty of the difference between the indicators of subgroup 1 and $3 ; p_{14}-$ the certainty of the difference between the indicators of subgroup 1 and 4

A correlation analysis was carried out to determine the relation of carbohydrate metabolism, blood pressure, and anthropometric parameters with the calcidiol level in blood serum (Table III). It was found that negative correlation of average strength was determined between $25(\mathrm{OH}) \mathrm{D}$ and the body weight of adolescents, BMI, BMIz, WC, HC, WHtR, WHR, basal insulin level, and HOMA-IR index of insulin resistance. There was no significant relationship between $25(\mathrm{OH}) \mathrm{D}$ and height, glucose levels in the blood, as well as the parameters of systolic and diastolic pressure.

Table IV presents the regression coefficients that characterise the determining contribution of the listed indicators of anthropometric measurements based on BMlz and carbohydrate metabolism in the formation of $25(\mathrm{OH}) \mathrm{D}$ level in blood plasma. The parameters that have a significant effect on the formation of calcidiol levels in blood serum and are statistically significant are basal insulin levels, body mass index, waist circumference, hip circumference, waist-hip ratio, and waist-height ratio.

The established standardised beta-regression coefficients allow comparison of the relative contributions of expected predictors in the development of vitamin $D$ deficiency in adolescents with obesity.

The conducted study found that in adolescents a low level of vitamin $D$ is determined, the concentration of which has a direct inverse correlation with body weight and body mass index $(p=0.000)$, waist circumference $(p=0.000)$, hip circumference $(p=0.001)$, waist-hip ratio $(p=0.000)$, waist-height ratio $(\rho=0.000)$, and the following carbohydrate markers: basal insulin level and HOMA-IR index. The associations between these indicators and their level of exposure to vitamin $\mathrm{D}$ are determined by the coefficients of the multiple regression analysis presented in Table IV. The obtained data of both nonstandardised and standardised regression coefficients confirm the results of correlation analysis.

The median content of vitamin $\mathrm{D}$ in adolescents with normal body weight was $17.6(12.03 ; 25.4) \mathrm{ng} / \mathrm{ml}$, with overweight $14.5(10.2 ; 20.6) \mathrm{ng} / \mathrm{ml}$, and with obesity - $12.7(9.3 ; 17.3) \mathrm{ng} / \mathrm{ml}$.

\section{Discussion}

There are scientific papers presenting results similar to ours, published by many researchers, who indicate that vitamin $D$ deficiency is most prevalent among children suffering from overweight and obesity [12-14]. It is believed that with excessive amounts of adipose tissue the sequestration of calcidiol increases within it, resulting in vitamin $D$ deficiency $[8,12]$. 
Table III. Interconnection of 25(OH)D level with anthropometric parameters, arterial pressure, and indicators of carbohydrate metabolism in adolescents with obesity

\begin{tabular}{lll}
\hline \multirow{2}{*}{ Parameters } & \multicolumn{2}{c}{ 25(OH)D } \\
\cline { 2 - 3 } & Correlation coefficient, $r$ & Certainty coefficient, $p$ \\
\hline Body weight & -0.427 & 0.000 \\
\hline BMI & -0.624 & 0.000 \\
\hline BMlz & -0.339 & 0.004 \\
\hline SBP & 0.082 & 0.384 \\
\hline DBP & -0.178 & 0.128 \\
\hline WC & -0.081 & 0.492 \\
\hline HC & -0.462 & 0.000 \\
\hline WHR & -0.369 & 0.001 \\
\hline WHtR & -0.398 & 0.000 \\
\hline Fasting blood glucose & -0.506 & 0.000 \\
\hline Basal insulin & -0.182 & 0.118 \\
\hline HOMA-IR & -0.544 & 0.000 \\
\hline
\end{tabular}

$\mathrm{BMI}$ - body mass index; BMIz - index of relative weight; SBP - systolic blood pressure; DBP - diastolic arterial pressure; WC - waist circumference; HC - hip circumference; WHR - waist-hip ratio; WHtR - ratio of waist circumference to height; HOMA-IR - insulin resistance index

Table IV. Results of multiple regression analysis of $25(\mathrm{OH}) \mathrm{D}$ with carbohydrate metabolism indices and anthropometric measurements based on BMIz in adolescents with obesity

\begin{tabular}{lllll}
\hline Predictor & $\mathrm{B}$ & Standard error, B & $\beta$ & Certainty coefficient, $p$ \\
\hline Body weight & -0.072 & 0.138 & -0.175 & 0.208 \\
\hline BMl & -1.394 & 0.459 & -0.861 & 0.001 \\
\hline WC & -1.693 & 0.755 & -3.856 & 0.026 \\
\hline HC & 0.636 & 0.962 & 1.947 & 0.511 \\
\hline WHR & -203.986 & 86.731 & -2.725 & 0.022 \\
\hline WHtR & 197.449 & 97.103 & 3.653 & 0.043 \\
\hline Basal insulin & -0.340 & 0.156 & -0.634 & 0.033 \\
\hline HOMA-IR & 1.106 & 0.609 & 0.447 & 0.103 \\
\hline Constant & 246.515 & 85.972 & & 0.001 \\
\hline
\end{tabular}

$\mathrm{B}$ - non-standardised coefficient of regression; $\beta$ - standardised regression coefficient; $\mathrm{R}=0.8012 ; \mathrm{R}^{2}=0.6419 ; \mathrm{F}=12.327 ; p<0.000 ;$ standard error estimation of the model: 3.150449 
The level of vitamin $D$ is affected by a number of factors, such as the season for the research, the use of vitamin D supplements, milk use, physical activity, lengthy working at a computer, and the duration of watching television [2, 13].

Most studies have highlighted that vitamin $D$ deficiency has a high correlation with abdominal obesity, and that vitamin D metabolites affect adipogenesis. Researchers emphasise that vitamin D contributes to the reduction of visceral fat through the mechanism of exposure to gene expression, which is associated with adipogenesis and oxidation of fatty acids [6].

In adolescents with overweight and obesity, there are disturbances in carbohydrate metabolism that are of varying degrees of severity, which is directly related to the state of vitamin D. In our study, impaired fasting glycaemia, basal insulin levels and HOMA-IR insulin resistance in patients with vitamin D deficiency was significantly higher than in patients with adequate levels of vitamin D. In children with obesity (Table III), correlation bonds of $25(\mathrm{OH}) \mathrm{D}$ with basal insulin levels and indices of insulin resistance HOMA-IR, as well as with BMI, were the highest.

With marked deficiency of vitamin D (subgroup 1), hyperinsulinaemia was determined, in which the level of insulin significantly exceeded the norm and was higher than that in the subgroups of children with a high level of vitamin D (subgroups 2 and 3) or its sufficient level (subgroup 4).

Hyperinsulinaemia, which develops in adolescents with vitamin D deficiency along with obesity, is associated with the development of insulin resistance and is directly correlated with serum 25(OH)D levels. The state of insulin resistance is associated with impaired sensitivity of cell membrane receptors as well as the permeability of calcium channels, which is directly dependent on the level of vitamin $D$ and is regulated by it $[9,14]$.

Vitamin D influences intracellular effects in the pancreatic B cells, their functional capacity through vitamin $D$ receptors, and the local membrane production of hydroxyvitamin D [15].

Due to the decrease in cellular sensitivity to insulin, the development of hyperinsulinaemia, and a disturbance in the balance between insulin production and glucose uptake, insulin resistance develops, which in our study is marked by the growth of HOMA-IR index. In children with obesity, there is a significant inverse correlation between the level of calcidiol and HOMA-IR index of average strength. In addition, our research has established a strong correlation between the HOMA-IR index and insulin $(r=0.954, p=0.000)$.

However, we have not established any significant differences in adolescents with obesity and overweight between blood glucose levels in subgroups with different concentrations of vitamin $D$ in serum. According to the correlation analysis, the correlation coefficient in children with overweight and obesity with glucose levels in the blood was $r=0.182$ and was not determined to be significant $(p=0.118)$.

Nevertheless, there are other studies that argue that in the case of concentration of $25(\mathrm{OH}) \mathrm{D}$ in blood plasma less than $15 \mathrm{ng} / \mathrm{ml}$, compared with the group with vitamin D level more than $26 \mathrm{ng} / \mathrm{ml}$, the chance for an increase in blood glucose levels regardless of obesity is twice as high.

The study of systolic and diastolic blood pressure determined the differences in the group of adolescents with a sufficient vitamin $\mathrm{D}$ level in comparison with adolescents with insufficiency and vitamin D deficiency; however, these differences were not statistically significant, and there was no correlation with the $25(\mathrm{OH}) \mathrm{D}$ level in blood serum. The findings confirm the results of other researchers concerning the absence of probable differences in systolic and diastolic pressure in adolescents with obesity at different vitamin D levels in blood plasma [16].

In spite of this, in some prospective studies, there is a relationship between low vitamin D level or its dietary intake and arterial hypertension. In particular, it is noted that giving vitamin $\mathrm{D}$ to patients with arterial hypertension for eight weeks leads to a significant reduction in blood pressure. In addition, there is evidence that vitamin $\mathrm{D}$ may be a negative endocrine regulator of the renin-angiotensin system. The researchers note that the activated metabolite 25(OH)D 1,25-dihydroxyvitamin $D$ inhibits renin gene expression [17]. Moreover, it is necessary to highlight the results obtained during the experimental studies that claim that in mice with zero vitamin $D$ receptor there is an increase in renin, systemic hypertension, and the development of hypertrophy of the heart.Also, we would like to point out the limitations of our study, which consisted of blood sampling in the autumn-winter period, when inadequate skin synthesis of vitamin $\mathrm{D}$ is common due to limited exposure to sunlight.

\section{Conclusions}

Vitamin D deficiency is prevalent in adolescents mostly with overweight and obesity.

Vitamin D deficiency is associated with hyperinsulinaemia, insulin resistance, and impaired fasting glucose in overweight and obese adolescents. There are the inverse correlations between vitamin D level and basal insulin level, insulin resistance index HOMA-IR. We did not find any interrelationship of calcidiol with impaired glucose tolerance.

Multiple logistic regression analysis showed that in the development of vitamin $D$ deficiency in overweight and obese adolescents the basal insulin level, body mass index, waist circumference, waist-hip ratio, and waist-height ratio are prognostically significant. 


\section{References}

1. Skyrda I, Petishko O, Hladun V, et al. Childhood obesity. Statistical evaluation of the prevalence in Ukraine: regional analysis. Epidemiology of Digestive System Diseases 2016; 1: 8-14. doi: 10.22141/2308-2097.1.59.2016.74457 [in Ukrainian]

2. Shulhai A-M, Pavlyshyn H, Shulhai O. Peculiarities of the prevalence and risk factors for vitamin d deficiency in overweight and obese adolescents in Ukraine. Arch Balk Med Union 2019; 54: 57-63. doi: 10.31688/ABMU.2019.54.1.08

3. Cheng S, Massaro J, Fox C, et al. Adiposity, Cardiometabolic Risk, and Vitamin D Status: The Framingham Heart Study. Diabetes 2010; 59: 242-248. doi: 10.2337/db09-1011

4. Weiss R, Dziura J, Burgert T, et al. Obesity and the metabolic syndrome in children and adolescents. N Engl J Med 2004; 350: 23622374. doi: 10.1056/NEJMoa031049

5. Li M, Qian M, Xu J. Vascular Endothelial Regulation of ObesityAssociated Insulin Resistance. Front Cardiovasc Med 2017; 51 : 1-9. doi: 10.3389/fcvm.2017.00051

6. Ruiz-Ojeda FJ, Anguita-Ruiz A, Leis R, et al. Genetic Factors and Molecular Mechanisms of Vitamin D and Obesity Relationship. Ann Nutr Metab 2018; 73: 89-99. doi: 10.1159/000490669

7. Cheng L. The Convergence of Two Epidemics: Vitamin D Deficiency in Obese School-aged Children. J Pediatr Nurs 2018; 38: 20-26. doi: 10.1016/j.pedn.2017.10.005

8. Olson M, Maalouf N, Oden J, et al. Vitamin D Deficiency in Obese Children and Its Relationship to Glucose Homeostasis. J Clin Endocrinol Metab 2012; 97: 279-285. doi: 10.1210/jc.2011-1507

9. Sethuraman U, Zidan MA, Hanks L, et al. Impact of vitamin D treatment on 25 hydroxy vitamin D levels and insulin homeostasis in obese African American adolescents in a randomized trial. J Clin Transl Endocrinol 2018; 12: 13-19. doi: 10.1016/j.jcte.2018.03.002
10. De Onis M, Blossner M. WHO Global Database on Child Growth and Malnutrition. Geneva, Switzerland: World Health Organization; 1997. https://apps.who.int/iris/bitstream/handle/10665/63750/WHO NUT _97.4.pdf;jsessionid =6AB752D1CF5CB5F8D5FC3662D5FE3D6B? sequence $=1$

11. Rusinska A, Pludowski P, Walczak M, et al. Vitamin D Supplementation Guidelines for General Population and Groups at Risk of Vitamin D Deficiency in Poland-Recommendations of the Polish Society of Pediatric Endocrinology and Diabetes and the Expert Panel With Participation of National Specialist Consultants and Representatives of Scientific Societies-2018 Update. Front Endocrinol (Lausanne) 2018; 9: 246. doi: 10.3389/fendo.2018.00246

12. Greene-Finestone L, Garriguet D, Brooks S, et al. Overweight and obesity are associated with lower vitamin D status in Canadian children and adolescents. Paediatr Child Health 2017; 22: 438-444. doi:10.1093/pch/pxx116

13. Hossain MJ, Levinson A, George D, et al. Vitamin D Status and Cardiovascular Risk in Obesity: Effect of Physical Activity in Nonvitamin D Supplemented Adolescents. Metab Syndr Relat Disord 2018; 16: 197-203. doi:10.1089/met.2017.0171

14. Gul A, Ozer S, Yılmaz R, et al. Association between vitamin D levels and cardiovascular risk factors in obese children and adolescents. Nutr Hosp 2017; 34: 323-329. doi: 10.20960/nh.412

15. Wimalawansa S. Associations of vitamin D with insulin resistance, obesity, type 2 diabetes, and metabolic syndrome. J Steroid Biochem Mol Biol 2018; 175: 177-189. doi:10.1016/j.jsbmb.2016.09.017

16. Peterson CA. Vitamin D deficiency and childhood obesity: Interactions, implications, and recommendations. Nutr Diet Suppl 2015; 7 : 29-39. doi: 10.2147/NDS.S52024

17. Rammos G, Tseke P, Ziakka S, et al. Vitamin D, the renin-angiotensin system, and insulin resistance. Int Urol Nephrol 2008; 40: 419-426. doi: 10.1007/s11255-007-9244-4 